\title{
Corrosion Penetration Monitoring of Advanced Ceramics in Hot Aqueous Fluids
}

\author{
Klaus G. Nickel*, Björn Seipel \\ University Tübingen, Germany, Institute for Geosciences, Applied Mineralogy \\ Wilhelmstr. 56, D-72074 Tuebingen
}

Received: September 2, 2002; Revised: September 4, 2002

\begin{abstract}
Advanced ceramics are considered as components in energy related systems, because they are known to be strong, wear and corrosion resistant in many environments, even at temperatures well exceeding $1000{ }^{\circ} \mathrm{C}$. However, the presence of additives or impurities in important ceramics, for example those based on Silicon Nitride $\left(\mathrm{Si}_{3} \mathrm{~N}_{4}\right)$ or $\mathrm{Al}_{2} \mathrm{O}_{3}$ makes them vulnerable to the corrosion by hot aqueous fluids. The temperatures in this type of corrosion range from several tens of centigrade to hydrothermal conditions above $100{ }^{\circ} \mathrm{C}$. The corrosion processes in such media depend on both $\mathrm{pH}$ and temperature and include often partial leaching of the ceramics, which cannot be monitored easily by classical gravimetric or electrochemical methods.

Successful corrosion penetration depth monitoring by polarized reflected light optical microscopy (color changes), Micro Raman Spectroscopy (luminescence changes) and SEM (porosity changes) will be outlined. The corrosion process and its kinetics are monitored best by microanalysis of cross sections, Raman spectroscopy and eluate chemistry changes in addition to mass changes. Direct cross-calibrations between corrosion penetration and mechanical strength is only possible for severe corrosion. The methods outlined should be applicable to any ceramics corrosion process with partial leaching by fluids, melts or slags.
\end{abstract}

Keywords: Ceramics, nitrides, aqueous, corrosion, penetration monitoring

\section{Introduction}

Advanced ceramics, which are used or considered for energy related systems, demonstrate corrosion resistance at higher temperatures than metals. A number of books and articles reviewing their behavior is available $\mathrm{e}^{1-4}$.

Oxide ceramics are naturally stable in oxygen-rich environments, which make them useful for applications at extreme temperatures. Alumina tubes operate in furnaces at $1800{ }^{\circ} \mathrm{C}$, zirconia is in use as a heater material in air well above $2000{ }^{\circ} \mathrm{C}$. Non-oxide ceramics based on silicon carbides and nitrides operate as structural materials at temperatures above $1200{ }^{\circ} \mathrm{C}$.

Because of their impressive chemical resistance at such conditions and the common use of glass and traditional ceramics in chemical laboratories it is often inferred that advanced ceramics should be almost invulnerable to corrosion at relatively low temperatures. The literature shows that this is not really true. Attack of aggressive aqueous media can deteriorate ceramics with secondary grain boundary phases even below $100{ }^{\circ} \mathrm{C}$ and many types are affected at higher temperatures under appropriate pressures.

This should not be confused with the attack by water vapor or steam. Wet atmospheres can accelerate oxidation and corrosion of non-oxides but this effect by itself is not dramatic $^{5-7}$. Wet atmospheres can transport alkalis and other impurities and thereby induce a further acceleration ${ }^{8}$ and at very high temperatures change the kinetics ${ }^{9-11}$. Some ceramics, based on $\mathrm{BN}, \mathrm{AlN}$ or $\mathrm{B}_{4} \mathrm{C}$ may be degraded completely ${ }^{12}$. However, at temperatures below about $1100{ }^{\circ} \mathrm{C}$ there will be little oxidation or corrosion of alumina, silicon carbides and nitrides in wet oxygen containing gaseous media.

It is the solution power of aqueous media for the oxides,

*e-mail: klaus.nickel@uni-tuebingen.de 
which make them dangerous to advanced ceramics. Thus water, as a fluid under supercritical conditions is likewise a corrosion medium, which is quite different from steam or wet atmospheres.

This opens the question about the applicability of advanced ceramics in energy related systems, where hot aqueous media have to be handled. If they interact with such fluids then the engineer needs to know the kinetics of the process in a given medium at a certain condition and a model for the consequences for the properties of the materials. Corrosion is a system property rather then a simple material property und for this reason it is not easy to obtain results, which can be transferred to other materials or conditions. This is one of the reasons why the classification for corrosion resistance in handbooks is rather vague ${ }^{13}$.

In this paper we will show how aqueous corrosion of advanced ceramics can be monitored, which is the first step in the development of lifetime prediction models. To do so, we have to discuss the mechanisms and the basic types of kinetics following from those.

\section{Corrosion Mechanisms}

\section{A. Pure ceramic phases}

In general the attack of water on the non-oxide ceramic phases is oxidizing, for example

$$
\begin{aligned}
& \mathrm{SiC}+2 \mathrm{H}_{2} \mathrm{O} \Leftrightarrow \mathrm{SiO}_{2}+\mathrm{CH}_{4} \\
& \mathrm{Si}_{3} \mathrm{~N}_{4}+6 \mathrm{H}_{2} \mathrm{O} \Leftrightarrow 3 \mathrm{SiO}_{2}+4 \mathrm{NH}_{3}
\end{aligned}
$$

The free energies of reactions (1) and (2) are strongly negative at room temperature, hence the thermodynamic equilibrium is on the side of the oxides. However, at room temperature, only surface reactions will take place and silica formers have a silanol $(\mathrm{SiOH}) \pm \operatorname{amine}\left(\mathrm{SiNH}_{2}\right)$-group ${ }^{14}$ coverage.

Reactions of the pure phases $\mathrm{SiC}$ and $\mathrm{Si}_{3} \mathrm{~N}_{4}$ with water have been evaluated by powder experiments. Data of Yoshimura et al. ${ }^{12,15}$ on SiC in water under $100 \mathrm{MPa}$ pressure indicated a insignificant amount of reaction below $500{ }^{\circ} \mathrm{C}$. This was confirmed in hydrothermal experiments on $\mathrm{SiC}$ fibers and crystals ${ }^{16,17}$. Experiments using $\mathrm{Si}_{3} \mathrm{~N}_{4}$ gave a strongly differing result, where the powder reacted below $200{ }^{\circ} \mathrm{C}^{15}$ and also pure HIPped and additive containing ceramic materials were reported to degrade at relatively low temperatures ${ }^{12}$. A threshold value of about $130{ }^{\circ} \mathrm{C}$ has been suggested $^{18}$.

As outlined below, the attack of aqueous media is via the oxide. Therefore the lack of reaction with water up to the boiling point makes both $\mathrm{SiC}$ and $\mathrm{Si}_{3} \mathrm{~N}_{4}$ as pure phases resistant to the attack by acid and caustic media. One exception are amorphous silicon nitride films, which can be etched, for example, by mixtures containing $\mathrm{H}_{2} \mathrm{O}_{2}$ and caustics at $70{ }^{\circ} \mathrm{C}^{14}$. Other exceptions are HF-containing systems. There is a rich literature on etching studies, to which the reader is referred to ${ }^{14,19-21}$.

To understand the general aqueous corrosion behavior we need to turn to the oxides, in particular to silica ${ }^{22}$. Silica can react and dissolve according to a sequence of reactions:

$\mathrm{SiO}_{2}+2 \mathrm{H}_{2} \mathrm{O} \Leftrightarrow \mathrm{H}_{4} \mathrm{SiO}_{4} \Leftrightarrow \mathrm{H}_{3} \mathrm{SiO}_{4}^{-}+H^{+} \Leftrightarrow \mathrm{H}_{2} \mathrm{SiO}_{4}^{2-}+2 H^{+}$

$\mathrm{H}_{4} \mathrm{SiO}_{4}$ is only a very weak acid with a limited solubility. Only at higher $\mathrm{pH}$-values, where hydrogen ions are removed, the reactions proceed towards the ions with a higher negative charge. Therefore silica solubility becomes significant above $\mathrm{pH}=9$ and very high at $\mathrm{pH}>11$. The solubility of amorphous silica in water rises from about $120 \mathrm{ppm}$ in neutral water to about $900 \mathrm{ppm}$ at $\mathrm{pH} 10.6$, the influence of rising temperatures is likewise to increase both solubility and dissolution rates ${ }^{24}$. Increasing pressure causes a nonlinear increase in solubility ${ }^{25}$. Depending on pressure, the solubility at about $\mathrm{T}>250{ }^{\circ} \mathrm{C}$ can drop again, because a less dense solution is making it progressively a poorer solvent for ionized species ${ }^{22}$.

Some solute constituents can increase the solubility of silica strongly, because they form complexes with $\mathrm{H}_{4} \mathrm{SiO}_{4}$ or $\mathrm{H}_{3} \mathrm{SiO}_{4}^{-}$. Namely $\mathrm{Fe}^{3+}$, but also $\mathrm{Mg}^{2+}$ and $\mathrm{Ca}^{2+}$ have been reported as well as a number of organic species. There is also a catalytic action of constituents like $\mathrm{Na}^{+}$, which strongly increase dissolution rates of silica already at low concentrations.

From the discussion above we can rationalize the difference of hydrothermal behavior of silicon carbide and silicon nitride: it is probably the change in $\mathrm{pH}$ of the water at the material surface, because the emission of $\mathrm{NH}_{3}$ according to reaction (2) induces the formation of $\mathrm{NH}_{4} \mathrm{OH}$, which dissociates to make a caustic solution. At room temperature, a $\mathrm{pH}$ between 9.5 and 10.5 has been measured ${ }^{26}$, the $\mathrm{pH}$ at hydrothermal conditions (100 $\mathrm{MPa}, 200-400{ }^{\circ} \mathrm{C}$ ) was not established.

From the strong change of reaction kinetics comparing $10 \mathrm{MPa}$ and $100 \mathrm{MPa}$-results ${ }^{27}$ it is clear that at $100 \mathrm{MPa}$ pressure there is no dissociation of $\mathrm{NH}_{3}$ into $\mathrm{N}_{2}$ and $\mathrm{H}_{2}$ at least up to $300{ }^{\circ} \mathrm{C}$ and that the alkalinity is high at those conditions.

The basic kinetics of hydrothermal corrosion of pure $\mathrm{Si}_{3} \mathrm{~N}_{4}$ in caustic aqueous media therefore have to be linear with time, because either the reaction to form the silica or the dissolution of silica in the medium is rate controlling. This has been suggested from powder experiments ${ }^{18}$ and is also true for the behavior of additive free HIPSN materials in strongly caustic media such as $1 \mathrm{n} \mathrm{NaOH}^{28}$.

It would exceed the article length if oxide ceramics would be discussed in great detail. Therfore we will only give short 
remarks here. The thermodynamic calculation of the reaction:

$$
\mathrm{Al}_{2} \mathrm{O}_{3}+3 \mathrm{H}_{2} \mathrm{O} \Leftrightarrow 2 \mathrm{Al}(\mathrm{OH})_{3}
$$

will favor the hydroxide at low temperature. However, the kinetic of pure corundum materials corrosion is so slow that water attack even at $300{ }^{\circ} \mathrm{C}$ is very low ${ }^{29}$.

Pure zirconia is likewise a very stable oxide. However, in particular the versions stabilized by further elements, are known for their susceptibility to aqueous corrosion in hydrothermal conditions and even at room temperature ${ }^{30}$.

\section{B. Glasses}

A great number of works on weathering and corrosion of glassy phases were published in the past and five classes of corrosion modes have been classified ${ }^{31}$. These modes are characterized by: I Hydrated surface layer $(\leq 5 \AA)$, II: Alkali-depleted surface layer, III: Silica-rich layer adjacent to bulk and cation rich layer adjacent to solution, IV: silicarich non-protective layer, V: no layer formation. The behavior is correlated with "durability" from high with type I to lowest with type $\mathrm{V}$.

This is compatible with the schematics outlined by Grambow $^{32}$ (Fig. 1). In this general model the glass surface becomes first hydrated and under appropriate conditions hydrolyzed, i.e. transformed into a gel, which has lost the glassy state (Corrosion mode III $^{31}$ ). Within this usually porous layer, which contains molecular water, there is a high ionic and water mobility. The gel layer interacts with the solution by exchanging ions with varying speed. Usually ions from network modifiers like alkalis are fast, while those from network formers are slow.

In particular acids, which have little power to dissolve silica, can extract network modifiers from glasses or gels with appropriate bonds ${ }^{33}$ :

$$
\equiv \mathrm{Si}-\mathrm{O}^{-} \mathrm{Na}^{+}+\mathrm{H}^{+} \Leftrightarrow \equiv \mathrm{Si}-\mathrm{OH}+\mathrm{Na}^{+}
$$

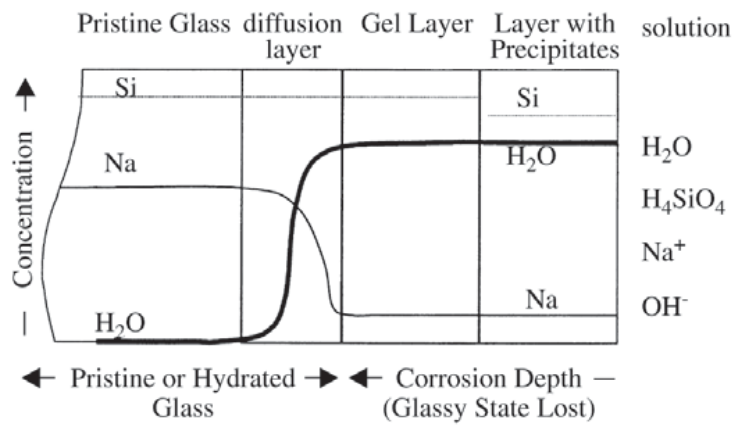

Figure 1. Schematic of the surface regions in corroded silicate glasses from ${ }^{32}$.
The consequence for the outer scale can be quite different. Either we have a silica- \pm network former-rich layer depleted in other elements or we find the complete dissolution of the glass. A third possibility is that secondary phases form at the boundary towards the solution, because small insoluble components become enriched.

From this simple picture we can predict the possible kinetic behavior. If the advance of the hydrolyzing front is fast, the dissolution of the gel in the solution slow and the ion exchange fast, we find profiles like the one of $\mathrm{Na}$ in Fig. 1: A very steep gradient very close to the boundary towards the pristine glass and the development of a depleted layer. Nonetheless, the overall kinetics are approximately parabolic, which is evidence for the transformation into gel to be rate controlling ${ }^{34}$. This is typical for the attack by acids.

If the water transport is slower, the diffusion profile for the alkalis will smear out over the whole gel-layer, the reaction is still controlled by diffusion of water through a growing layer: again the first approximation is a parabolic or near parabolic kinetic.

If the dissolution of the whole glass is rate controlling it can be treated like a first order chemical reaction and the dissolution is expected to be constant with time, i.e. linear kinetics should prevail. In cases, where minor elements become concentrated, precipitate and form protective layers the linear kinetics will be retarded: parabolic or logarithmic kinetics follow.

For the action of pure water on complex glasses we find a process with simultaneous factors: the ion exchange of alkalis with $\mathrm{H}^{+}$and the dissolution of the network-forming silica (or other network-forming elements, such as Al, B and $\mathrm{Zr}$ ), according to Eqs. (5) and (6)

$$
\mathrm{Si}-\mathrm{O}-\mathrm{Si}+\mathrm{OH}^{-} \Rightarrow \mathrm{Si}-\mathrm{O}^{-}+\mathrm{Si}-\mathrm{OH}
$$

At short times the exchange-reaction with parabolic kinetics is dominating, which makes the $\mathrm{pH}$ rise and initiate the glass dissolution, which is then acting with linear kinetics at longer times.

Both reaction rates and diffusion profiles depend strongly not only on external conditions like pressure, temperature and flow/exchange of media, but also on the composition of the glass at hand, which is different for every glass and can change during the process. Attempts have been made to predict corrosion behavior from the composition ${ }^{35}$ but have not proven successful in simple well controlled experiments at $\mathrm{pH}=7^{24}$. A summary of surface layer effects on glass corrosion is given by Feng et al. ${ }^{36}$, important details can be found in Darby et al. ${ }^{37}$.

Thus only general rules follow from the mechanisms described. For example, it is expected to have less corrosion by acids if the glass contains more silica, because this is not harmed by the solution, while this will increase at- 
tack by basic solutions. Similarly, we can expect decreasing corrosion in acids by improving the bond strengths of network modifiers in the glass: alkaline earth elements should corrode less then alkali elements. Further arguments for the influence of the bonding structure comes from findings that silicon oxycarbide glasses have a much better resistance against alkaline solutions or HF compared with phase separated glasses of the same composition ${ }^{38}$. Aluminium and boron can improve the durability of glasses, depending on amount and solute $\mathrm{pH}$. Nitrogen incorporation can increase the resistance against alkaline solutions. Concentrated acids or bases corrode less then moderate concentrated solutes, which may be attributed to lower solubility for reaction products or decreasing water activity ${ }^{39}$.

\section{Advanced ceramics with grain boundary phases}

Most of the materials, which may be considered for energy related systems, will have a grain boundary phase, because the economic industrial production usually involves sintering additives to obtain dense ceramics.

From the discussion of the mechanisms above it is clear that ceramics with glassy grain boundary phases should behave different from pure phases. This is the case. An extreme example has been reported for alumina ceramics, where it has been shown that impurities as low as 500 ppm $\mathrm{SiO}_{2}$ cause dramatic differences ${ }^{40}$. The impurity leads to the existence of a continuous grain boundary phase, which was rapidly leached in boiling $10 \% \mathrm{H}_{2} \mathrm{SO}_{4}$, while the ceramic without it was practically untouched.

The same is true for $\mathrm{SiC}$ and $\mathrm{Si}_{3} \mathrm{~N}_{4}$. If there is a secondary phase like $\mathrm{Si}$ in $\mathrm{SiSiC}^{41}$ or a glassy silicate grain boundary phase in liquid phase sintered $\mathrm{SiC}$ or $\mathrm{Si}_{3} \mathrm{~N}_{4}$, then this component dominates the process ${ }^{21}$ at least below $100{ }^{\circ} \mathrm{C}$. Under hydrothermal conditions the grain boundary phase can make the material both less or more resistant to aqueous corrosion than the pure phase $\mathrm{e}^{42}$. The corrosion is then via selective attack, which makes the calculation of penetration depths difficult, imprecise or impossible.

\section{Corrosion monitoring}

From the discussion of the mechanisms it is clear that the corrosion processes can follow quite variable kinetic patterns. The shape of such a curve may be anticipated in some cases, the exact prediction of the curve is not possible.

One of the reasons for the difficulties is that a rate control by dissolution or leaching processes means that the actual velocity of corrosion is strongly dependent on the physical boundary conditions: surface area exposed, defect concentrations, flow velocity and flow type (stagnant, laminar, turbulent) of the media will all have an influence. And the conditions, to which of a material in an energy related system is subjected, will vary strongly.
Standard corrosion experiments can create additional problems, because the criterion for comparability may be violated: saturation and $\mathrm{pH}$-change effects in fixed volume experiments are not uncommon ${ }^{32}$. Thus for an evaluation of the actual performance is necessary to simulate the process at hand with appropriate experiments and evaluate the process by monitoring. A life time prediction beyond the experimental times necessitates a good understanding of the acting mechanisms and this can only be done by a combination of monitoring methods: mass change, fluid composition, analyses of cross sections and properties.

The possibilities will be demonstrated for the corrosion of a sintered silicon nitride in sulfuric acid. The chosen material was deliberately of a type very susceptible to corrosion in order to create large, measurable effects.

\section{A. Material and Experimental Setup}

A gas pressure sintered $\mathrm{Si}_{3} \mathrm{~N}_{4}$ with 6 wt. $\% \mathrm{Y}_{2} \mathrm{O}_{3}$ and 4 wt. $\% \mathrm{Al}_{2} \mathrm{O}_{3}$ with $99.5 \%$ density prepared by IKTS Dresden was used in the corrosion tests in diluted sulphuric acid. XRD investigations did not show any indication for crystalline phases within the grain boundaries.

The samples were cut and ground into rectangular $3.5 \times 3 \times 45 \mathrm{~mm}$ beams. These were inserted in a teflon (PTFE) corrosion cell with continuous flow, which is described elsewhere ${ }^{43}$. The flow rate of $0.24 \mathrm{ml} / \mathrm{min}$ through the corrosion cell $(30 \mathrm{ml})$ ensured a replacement of the corroding agent approximately every $2 \mathrm{~h}$. This setup was used to exclude overall saturation effects to play a role. With an oil bath a temperature of $90{ }^{\circ} \mathrm{C}$ was kept with a precision of $\pm 1{ }^{\circ} \mathrm{C}$.

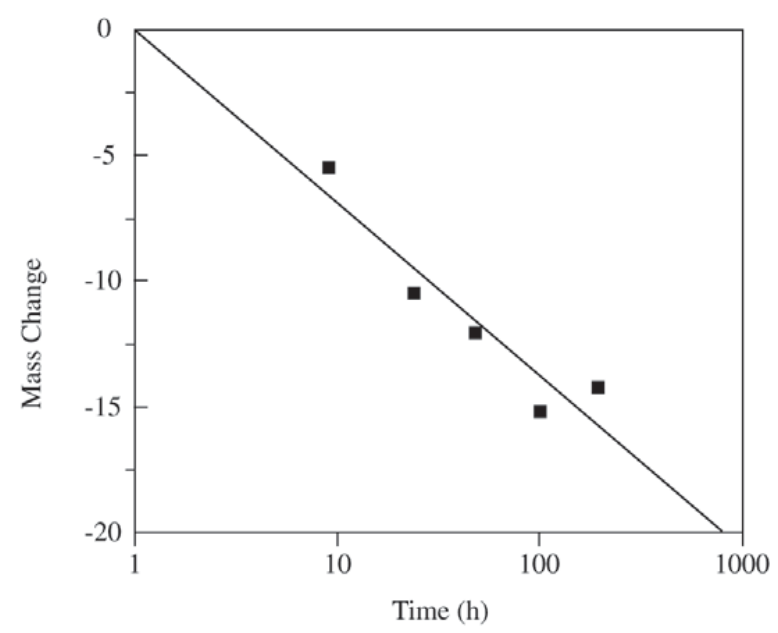

Figure 2. Mass change of $\mathrm{Si}_{3} \mathrm{~N}_{4}$ sample exposed to $1 \mathrm{n}_{2} \mathrm{SO}_{4}$ at $90{ }^{\circ} \mathrm{C}$. 


\section{B. Mass change}

The most widely used monitor parameter is the mass change after a given treatment. The results for the $\mathrm{Si}_{3} \mathrm{~N}_{4}$ corroded by $1 \mathrm{n}_{2} \mathrm{SO}_{4}$ at $90{ }^{\circ} \mathrm{C}$ are shown in Fig. 2 .

Figure 2 is an example for a corrosion, which seems to follow a logarithmic trend, i.e. the fast mass losses of the initial period seem to cease after some time. Such curves are known from glasses in strong acids ${ }^{44}$. However, the mechanisms cannot be determined from this result. Passivation or the balancing of processes operating in different directions are possible.

Often mass changes due to corrosion in aqueous media are much smaller $\left(\mu \mathrm{g} / \mathrm{cm}^{2}\right.$ range), which makes the interpretation more difficult, because minute losses due to sample handling will interfere with the result. As a single parameter the mass change is not conclusive.

\section{Eluate chemistry}

The change in eluate chemistry can be followed easily in experiments with continuous flow. Here at a chosen time a separate eluate sample is taken. This allows the evaluation of the amount going into the medium at a given time instead of analyzing the content of a fixed volume, which becomes more and more concentrated.

The results of measurements by atomic absorption spectroscopy (AAS) and ICP-MS for the $\mathrm{Si}_{3} \mathrm{~N}_{4}$ is shown in Fig. 3. Obviously we have a decrease of all elements going into solution with time, which is approximated by an exponential trend in Fig. 3. This is a first indication of the mechanism operating: the result is compatible with the assump-

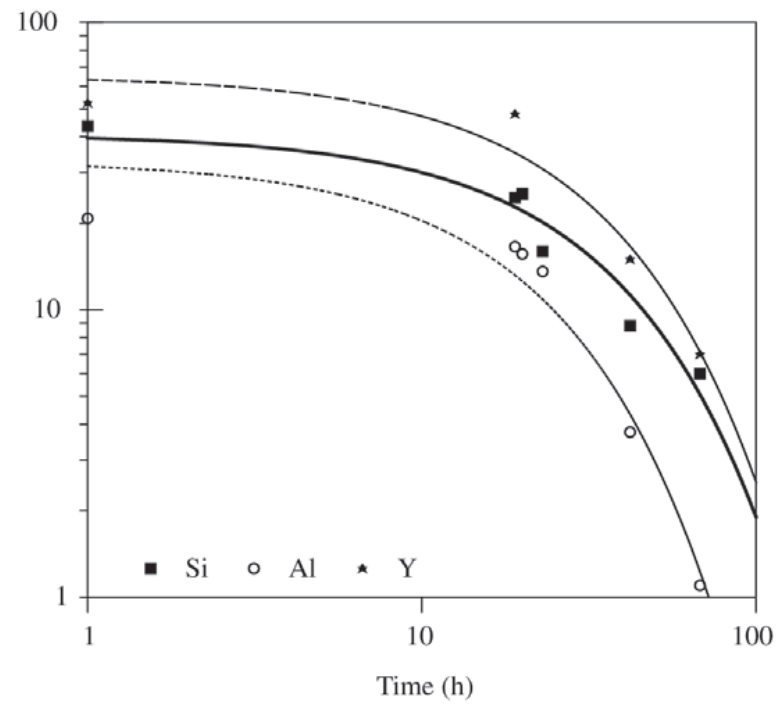

Figure 3. Concentrations of $\mathrm{Si}, \mathrm{Al}$ and $\mathrm{Y}$ in eluats taken at the indicated time, corroding $\mathrm{Si}_{3} \mathrm{~N}_{4}$ sample by $1 \mathrm{n}_{2} \mathrm{SO}_{4}$ at $90{ }^{\circ} \mathrm{C}$. tion of a slowing down of the process.

The retardation speed seems not to be compatible with a parabolic law. Thus simple explanations with diffusion control will not be satisfactory.

\section{Cross section analysis}

In all cases where corrosion is preferentially along grain boundaries the penetration can not be calculated directly from mass changes, unless the distribution of this phase is analyzed. Thus, for penetration depths the evaluation will have to be with the aid of cross sections.

For a qualitative evaluation, often an investigation by reflected light microscopy is sufficient (Fig. 4). The altered

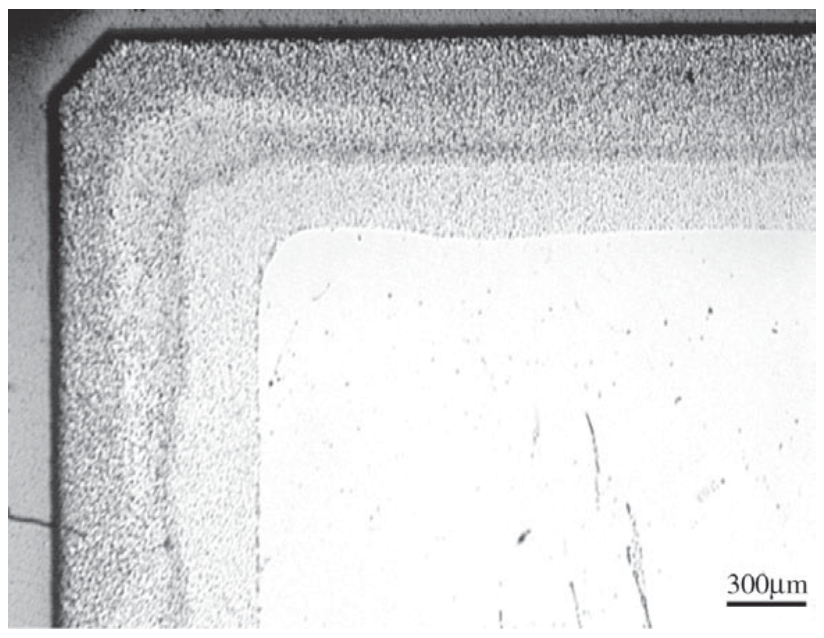

Figure 4. Cross section of $\mathrm{Si}_{3} \mathrm{~N}_{4}$ sample exposed for $100 \mathrm{~h}$ to $1 \mathrm{n}$ $\mathrm{H}_{2} \mathrm{SO}_{4}$ at $90{ }^{\circ} \mathrm{C}$ in reflected polarised light microscopy from ${ }^{43}$.

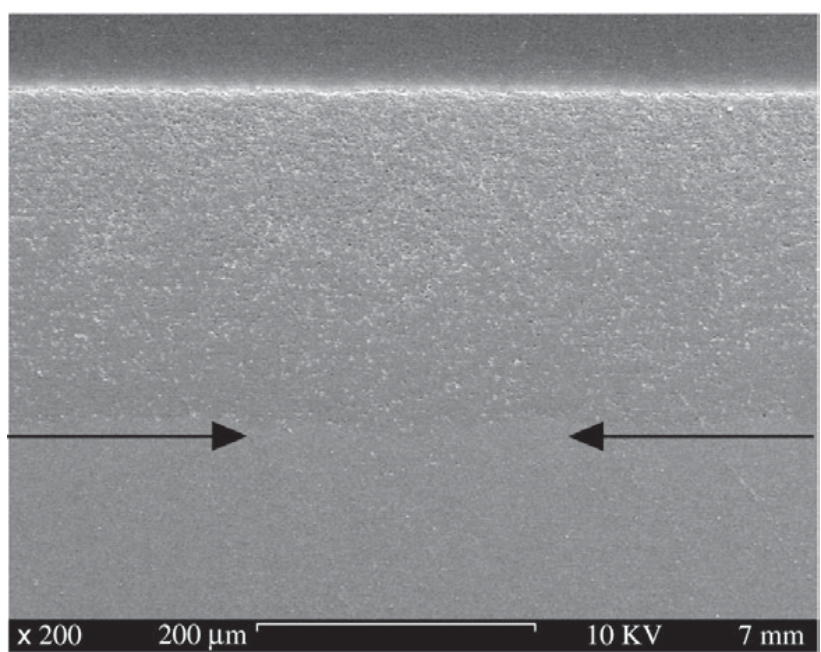

Figure 5. Cross section of $\mathrm{Si}_{3} \mathrm{~N}_{4}$ sample exposed for $100 \mathrm{~h}$ to $1 \mathrm{n}$ $\mathrm{H}_{2} \mathrm{SO}_{4}$ at $90^{\circ} \mathrm{C}$ as observed by REM. The arrows mark the change from the porous corroded zone to base material. 


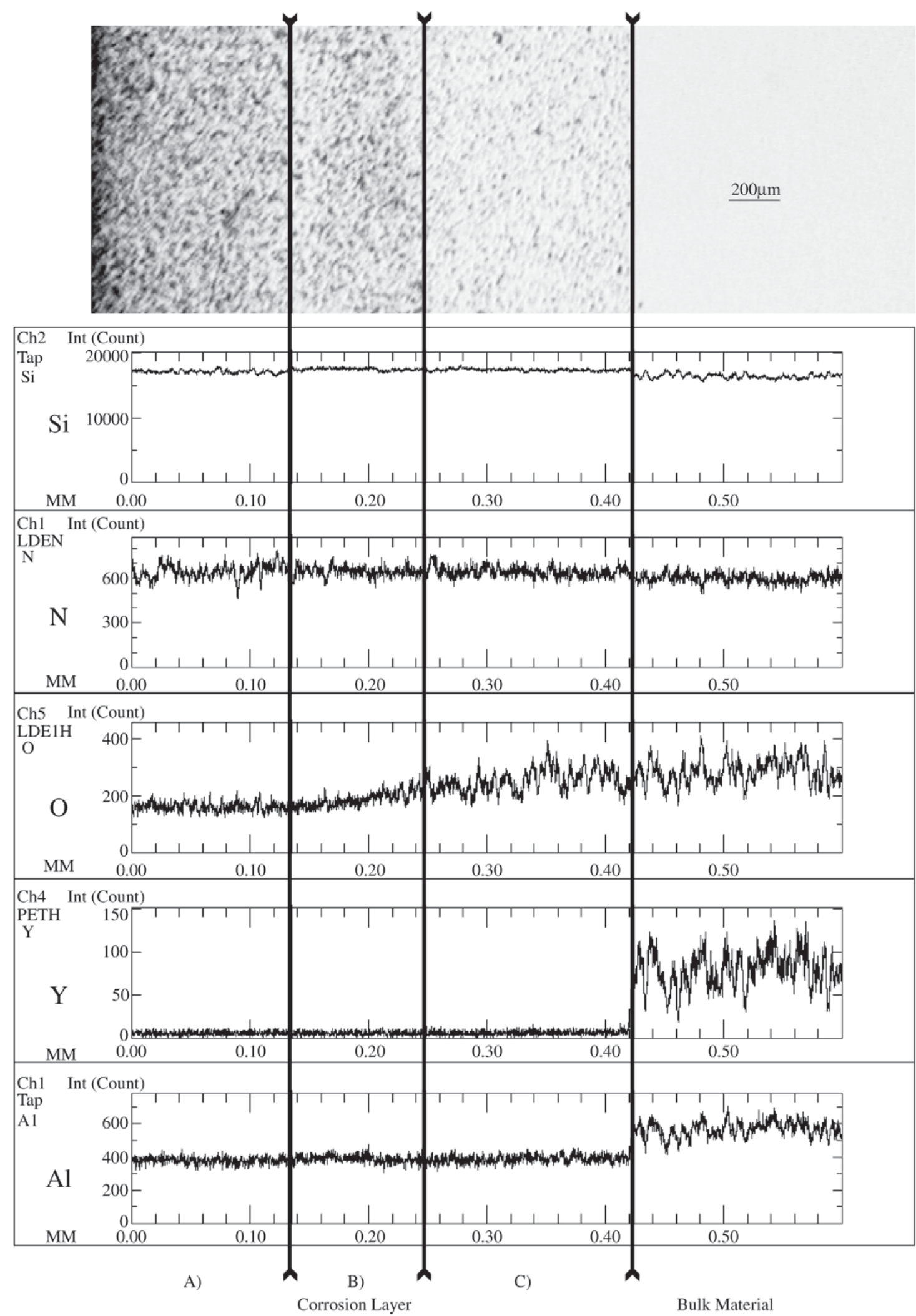

Figure 6. Linescan my microprobe across the corrosion layer in comparison with the optical mi crograph (top) after ${ }^{43}$. 
zone is clearly visible. The differences in reflectivity indicate a structured corrosion zone.

The chamfer on the sample on the top left corner is well preserved and provides evidence for the preservation of the original geometry, which, in turn, is evidence for the process of grain boundary corrosion without matrix degradation.

In cross sections of corroded $\mathrm{Si}_{3} \mathrm{~N}_{4}$ observed by REM (Fig. 5) the corrosion front is visible by porosity changes. It can be seen that the porosity is not continuous within the corroded zone. However, if we have a gradual decrease of porosity with depths or rather a layered structure with diffuse boundaries is hard to decide. The comparison with the optical micrograph (Fig. 4) is arguing for a structured feature.

Chemical profiling of the corroded layer is possible with a number of techniques. An example is electron microprobe analysis in wavelengths dispersive mode. This is shown in Fig. 6.

From Fig. 6 it is clear that the corroded zone has a complete loss of $\mathrm{Y}$ and $\mathrm{Al}$ from the glass phase (some $\mathrm{Al}$ remains in $\mathrm{Si}_{3} \mathrm{~N}_{4}$ ). The concentration profile is thus akin to the schematic of Fig. 1. The nitrogen profile provides further evidence that no $\mathrm{Si}_{3} \mathrm{~N}_{4}$ is lost by corrosion. The oxygen profile reveals three or four different zones. The solution side contains no oxygen; hence it represents a zone of near complete dissolution. Further in we have signals of oxygen, which may be interpreted as continuously increasing towards the zone of pristine material or as a field with two zones $\mathrm{B}$ and $\mathrm{C}$ in Fig. 6, which must contain leached silica.

The structure of the phases within the corroded zone cannot be evaluated by chemical profiles. However, the luminescence as observed by Raman spectroscopy (Fig. 7) provides evidence for strongly disordered silica in corrosion zone $\mathrm{C}$ of Fig. 6, the gel formation according to Fig. 1 is a likely mechanism. Very interesting is the luminescence of zone B of Fig. 6. There is no simple monotonous decrease in the amount of silica towards the solution. The pattern may be interpreted as evidence for the precipitation of phases or structures, which correspond to the outer zone in Fig. 1 and which may be responsible for the retardation of the corrosion process with time.

The monitoring of the effect of corrosion on mechanical properties of the ceramics is very cost- and time consuming, because a large number of samples is needed to establish a significant value for brittle materials 45 . For extensive corrosion, a direct link between the extent of corrosion and loss of strength is evident as shown in Fig. 8.

However, this needs not to be the case. The failure of brittle materials is from existing flaws of critical size. If flaws are created by and grow with corrosion they will not be detected as long as they are smaller then the pre-existing flaws. So there may be a discontinuous behavior with a seemingly unchanged strength for long times, followed by a sudden change in properties.

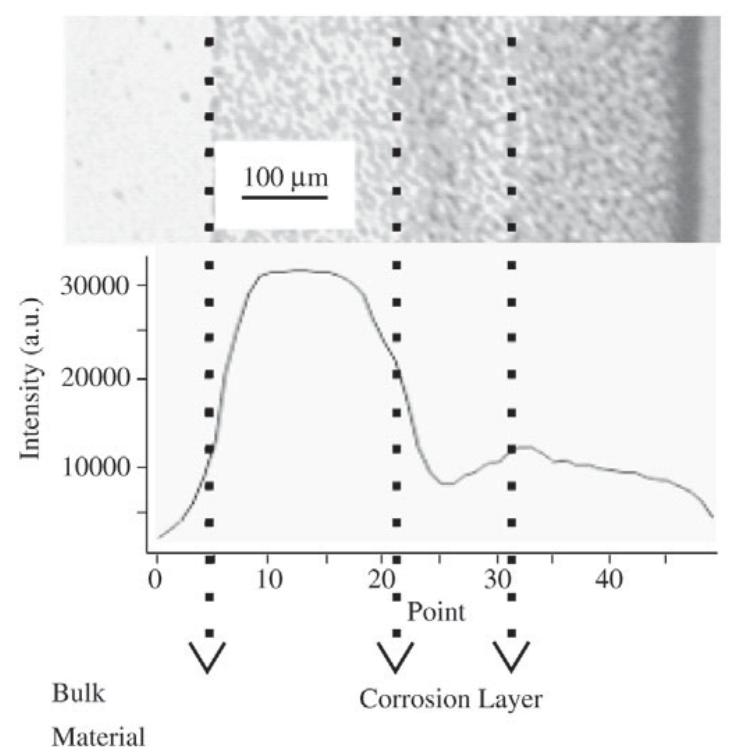

Figure 7. Linescan by Micro Raman Spectroscopy showing relative luminscence intensities of the zones depicted in Fig. 6 from ${ }^{43}$.

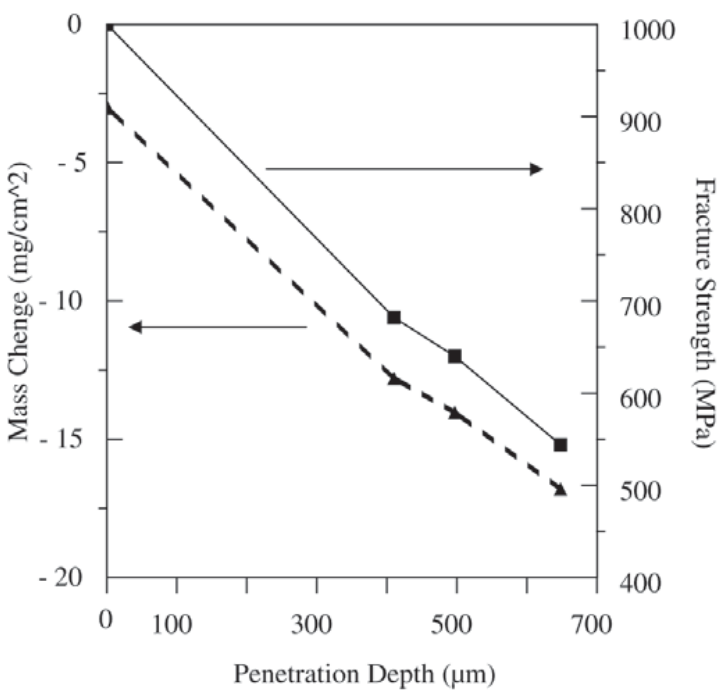

Figure 8. Correlation of mass change, penetration and fracture strength for the $\mathrm{Si}_{3} \mathrm{~N}_{4}$ described in the text

\section{Conclusions}

- Aqueous media can attack advanced ceramics.

- At temperatures below $100^{\circ} \mathrm{C}$ the attack is related to the presence of impurities and grain boundary phases, the matrix phases are not significantly degraded. At hydrothermal conditions, Si3N4 matrix phases become susceptible at temperatures above about $150^{\circ} \mathrm{C}$, 
$\mathrm{SiC}$ and alumina as pure phases are resistant to higher temperatures.

- The grain boundary phase can be tailored to meet specific demands, e.g. to be acid resistant.

- The selective corrosion makes grain boundary attack the dominant corrosion type. The effect is not reliably predictable and has to be monitored by experiments simulating application conditions.

- Several methods of monitoring (mass change, eluate chemistry, cross section analysis by optical microscopy, chemical profiling and Raman spectroscopy) can be successfully employed. For the analysis of mechanisms and to establish a predictive tool a combination of such methods is necessary. Subsequently, low-cost monitoring by optical means may be sufficient.

- There is a strong correlation between the strength of the ceramics and corrosion progress in severely corroded samples. The correlation is however not so straightforward in all cases.

\section{Acknowledgements}

We gratefully acknowledge funding from the German Research Association (DFG) under Ni299/7. We like to thank Dr. Westerheide, Dr. Herrmann and J. Schilm from the Fraunhofer-Institutes for the mechanics of materials (IWM, Freiburg) and for ceramics and sintering technology (IKTS, Dresden) and Prof. Y. Gogotsi (Drexel University) for collaboration and many fruitful discussions.

\section{References}

1. Gogotsi, Y. G. and Lavrenko, V. A., Corrosion of HighPerformance Ceramics, Springer Verlag, Berlin, F.R.G., 1992.

2. Corrosion of Advanced Ceramics - Measurement and Modelling; Vol. 267, edited by Nickel, K. G. (Kluwer Academic Publisher, Dordrecht, NL, 1994).

3. Nickel, K. G. and Quirmbach, P., in Technische Keramische Werkstoffe, edited by Kriegesmann, J. (Deutscher Wirtschaftsdienst, Köln, 1991), p. Chapter 5.4.1.1., p. 1-76.

4. Fordham, R. J., Baxter, D. J., and Graziani, T., Corrosion of Advanced Ceramics, Vol. 113, TransTech Pub., Zurich, CH, 1995.

5. Opila, E. J., J.Am.Ceram.Soc. v. 77, p. 730-736, 1994.

6. Schumacher, C., Nickel, K. G., and Thaler, H., in WerkstoffWoche 98; Vol. 3, edited by Kranzmann, A. and Gramberg, U. (Wiley-VCH, Weinheim, 1999), p. 25-30.

7. Opila, E. J., J.Am.Ceram.Soc. v. 82, p. 625-636, 1999.

8. Opila, E., J.Am.Ceram.Soc. v. 78, p. 1107-1110, 1995.

9. Cappelen, H., Johansen, K. H., and Motzfeld, K., Acta
Chem.Scand. v. A 35, p. 247-254, 1981.

10. Opila, E. J. and Hann Jr., R. E., J.Am.Ceram.Soc. v. 80, p. 197-205, 1997.

11. More, K. L., Tortorelli, P. F., Ferber, M. K., and Keiser, J. R., J.Am.Ceram.Soc. v. 83, p. 211-213, 2000.

12. Gogotsi, Y. G. and Yoshimura, M., MRS Bull. v. 1994, p. 39-45, 1994.

13. Morell, R., Handbook of properties of technical \& engineering ceramics, HMSO books, London, 1987.

14. Sangster, R. C., Kämpf, P., and Nohl, U., Silicon Suppl. B 5d2, Vol. 15, Springer-Verlag, Berlin, 1995.

15. Yoshimura, M., Kase, J., Hayakawa, M., and Somiya, S., in Corrosion and Corrosive Degradation of Ceramics, edited by Tressler, R. E. and McNallan, M. (Am.Ceram.Soc., 1990), p. 337-354.

16. Kraft, T., Nickel, K. G., and Gogotsi, Y. G., J.Mat.Sci. v. 33, p. 4357-4364, 1998.

17. Kraft, T. and Nickel, K. G., J.Mat.Chem. v. 10, p. 671680., 2000.

18. Nickel, K. G., Däumling, U., and Weißkopf, K., Key Eng.Mat. v. 89-91, p. 295-300, 1994.

19. Sato, T., Tokunaga, Y., Endo, T., Shimada, M., Komeya, K., Nishida, K., Komatsu, M., and Kameda, T., J.Mat.Sci. v. 23, p. 3440-3446, 1988.

20. Knotter, D. M. and Denteneer, T. J. J. D., J.Electrochem.Soc. v. 148, p. 43-46, 2001

21. Sharakawy, S. W. and El-Aslabi, A. M., Corrosion Science v. 40, p. 1119-1129, 1998.

22. Dove, P. M. and Rimstidt, J. D., in Silica; Vol. 29, edited by Heaney, P. J., Prewitt, C. T., and Gibbs, G. V. (Mineralogical Society of America, Washington, 1994), p. 259-308.

23. Iler, R. K., The Chemistry of Silica, Wiley, London, 1979.

24. Perera, G., Doremus, R. H., and Lanford, W., J.Am.Ceram.Soc. v. 74, p. 1269-1274, 1991.

25. Fournier, R. O. and Rowe, J. J., Am.Min. v. 62, p. 10521056, 1977.

26. Däumling, U., Diploma Thesis (M.Sc.) Thesis, EberhardKarls-Univertität Tübingen, 1993.

27. Yoshimura, M., Kase, J., and Somiya, S., in Oxidation of Si3N4 and SiC by High Temperature-High Pressure Water Vapor, Germany, 1986, p. 529-536.

28. Herrmann, M., Klemm, H., and Schubert, C., in Handbook of Ceramic Hard Materials, edited by Riedel, R. (Wiley-VCH, Weinheim, 2000), p. 749-801.

29. Oda, K. and Yoshio, T., J.Am.Ceram.Soc. v. 80, p. 32333236, 1997.

30. Kimel, R. A. and Adair, J. H., J.Am.Ceram.Soc. v. 85, p. 1403-1408, 2002.

31. Pantano, C. G., Clark, D. E., and Hench, L. L., Corrosion of Glass, Books for Industry, New York, 1979.

32. Grambow, B., in Uhlig's Corrosion Handbook, 2 ed., edited by Revie, R. (John Wiley \& Sons, New York, 
2000), p. 411-437.

33. Moore, J. M., Clark, D. E., and Simmons, J. H., Ceramic Transactions v. 101, p. 153-158, 2000.

34. Scholze, H., Glas, 3.rd edition ed., Springer-Verlag, Berlin, 1988.

35. Jantzen, C. M. and Plodinec, M. J., J.Non-Cryst.Solids v. 67, p. 207-223, 1984.

36. Feng, X., Mat.Res.Soc.Symp.Proc. v. 333, p. 55-68, 1994.

37. Darby, G., Clark, D. E., and Simmons, J. H., Ceramic Transactions v. 101, p. 141-151, 2000.

38. Sorarù, G. D., Modena, S., Guadagnino, E., Colombo, P., Egan, J., and Pantano, C., J.Am.Ceram.Soc. v. 85, p. 1529-1536, 2002.

39. Elmer, T. H., J.Am.Ceram.Soc.Comm. v. 68, p. C-273274, 1985.

40. Meyer, H., in Technische Keramische Werkstoffe; Vol.
Kap. 5.4.1.2.1., edited by Kriegesmann, J. (Deutscher Wirtschaftsdienst, Köln, 1999), p. 1-15.

41. Wendland, K., Hollstein, T., Pfeiffer, W., Heinrich, J., and Zeus, D., in Korrosion und VerschleiO von keramischen Werkstoffen, edited by Telle, R. and Quirmbach, P. (DKG, Köln, 1994), p. 107-113.

42. Herrmann, M., Michael, G., Schubert, C., and Hermel, W., in Werkstoffwoche '98; Vol. 3, edited by Kranzmann, A. and Gramberg, U. (Wiley-VCH, Weinheim, 1998), p. 281-286.

43. Seipel, B. and Nickel, K. G., J.Europ.Ceram.Soc. v. 23, p. 595-602, 2003.

44. Doremus, R. H., Glass Science, 2 ed., John Wiley \& Sons, N.Y., 1994.

45. Munz, D. and Fett, T., Ceramics : Mechanical Properties, Failure Behaviour, Materials Selection, Vol. 36, Springer, Berlin, 1999. 